\title{
Developmental adaptation of the mouse cardiovascular system to elastin haploinsufficiency
}

\author{
Gilles Faury, ${ }^{1}$ Mylène Pezet,${ }^{1}$ Russell H. Knutsen, ${ }^{2}$ Walter A. Boyle, ${ }^{3}$ Scott P. Heximer, ${ }^{2}$ \\ Sean E. McLean, ${ }^{2}$ Robert K. Minkes, ${ }^{4}$ Kendall J. Blumer, ${ }^{2}$ Attila Kovacs, ${ }^{5}$ Daniel P. Kelly, \\ Dean Y. Li, ${ }^{6}$ Barry Starcher, ${ }^{7}$ and Robert P. Mecham ${ }^{2}$ \\ ${ }^{1}$ Laboratoire de Développement et Vieillissement de l'Endothélium, Département de Réponse et Dynamique Cellulaires, \\ Commisarriat à l'Energie Atomique/Institut National de la Santé et de la Recherche Médicale-Equipe Mixte 0219, \\ Université Joseph Fourier, Grenoble, France \\ ${ }^{2}$ Department of Cell Biology and Physiology, \\ ${ }^{3}$ Anesthesiology Research Unit, \\ ${ }^{4}$ Department of Surgery, and \\ ${ }^{5}$ Center for Cardiovascular Research, Washington University School of Medicine, St. Louis, Missouri, USA \\ ${ }^{6}$ Cardiology Division and Program in Human Molecular Biology and Genetics, University of Utah Health Sciences Center, \\ Salt Lake City, Utah, USA \\ ${ }^{7}$ Department of Biomedical Research, University of Texas Health Center, Tyler, Texas, USA
}

\begin{abstract}
Supravalvular aortic stenosis is an autosomal-dominant disease of elastin (Eln) insufficiency caused by loss-of-function mutations or gene deletion. Recently, we have modeled this disease in mice $\left(E h^{+/-}\right)$ and found that Eln haploinsufficiency results in unexpected changes in cardiovascular hemodynamics and arterial wall structure. $E l n^{+/-}$animals were found to be stably hypertensive from birth, with a mean arterial pressure $25-30 \mathrm{mmHg}$ higher than their wild-type counterparts. The animals have only moderate cardiac hypertrophy and live a normal life span with no overt signs of degenerative vascular disease. Examination of arterial mechanical properties showed that the inner diameters of $\mathrm{Eln}^{+/-}$arteries were generally smaller than wild-type arteries at any given intravascular pressure. Because the $\mathrm{Eln}^{+/-}$mouse is hypertensive, however, the effective arterial working diameter is comparable to that of the normotensive wild-type animal. Physiological studies indicate a role for the reninangiotensin system in maintaining the hypertensive state. The association of hypertension with elastin haploinsufficiency in humans and mice strongly suggests that elastin and other proteins of the elastic fiber should be considered as causal genes for essential hypertension.
\end{abstract}

J. Clin. Invest. 112:1419-1428 (2003). doi:10.1172/JCI200319028.

\section{Introduction}

The physiological demands of the arterial system in vertebrates require that arteries store energy during systole and release it during diastole, which allows the heart to work at an optimal rate and stroke volume. The central feature that facilitates this function is vessel elasticity, which is conferred upon the arterial wall

Received for publication May 27, 2003, and accepted in revised form August 26, 2003.

Address correspondence to: Robert P. Mecham, Department of Cell Biology and Physiology, Washington University School of Medicine, Box 8228, 660 South Euclid Avenue, St. Louis, Missouri 63110, USA. Phone: (314) 362-2254; Fax: (314) 362-2252; E-mail: bmecham@cellbiology.wustl.edu. Conflict of interest: The authors have declared that no conflict of interest exists.

Nonstandard abbreviations used: smooth muscle cells (SMCs); supravalvular aortic stenosis (SVAS); Williams syndrome (WS); inner diameter (ID); outer diameter (OD); phenylephrine (PE); acetylcholine (Ach); wall cross-sectional area (WCSA); distensibility per $25 \mathrm{mmHg}$ increment $\left(\mathrm{D}_{25}\right)$; left ventricle (LV); systolic LV volume (LVV); diastolic LV volume (LVVd); least significant difference (LSD); mean arterial pressure (MAP); left ventricular volume indexed to body weight (LVVdI); end-systolic left ventricular volume (LVVsI); renin-angiotensin system (RAS). by the apposition of smooth muscle cells (SMCs) and a complex weave of ECM molecules. The basic morphological plan of large arteries present in all major vertebrate classes consists of repeating concentric layers of SMCs separated by elastic fibers that form interconnected fenestrated sheets, or lamellae. These elastic lamellae are designed to function as an elastic reservoir and to distribute tension uniformly throughout the vessel wall. The number of lamellar units (generally defined as the elastic lamella and adjacent SMCs) in a vascular segment is related linearly to tensional forces within the wall (1-3), with the greatest number of elastic layers occurring in the larger, more proximal vessels that experience the highest wall stress.

Acquired elastic fiber abnormalities that alter the structure and mechanical properties of vessels are associated with aging and are observed in common vascular diseases, such as atherosclerosis, aneurysms, and hypertension. Other vascular diseases have been shown to have a genetic etiology. At least three clinical conditions have been linked to mutation or deletion of the elastin gene $(E l n)$. Autosomal dominant cutis laxa, a primarily cutaneous condition, is the result of frameshift 
mutations at Eln that influence elastic fiber structure through a dominant negative effect $(4,5)$. Supravalvular aortic stenosis (SVAS), an autosomal-dominant disorder, is caused by intragenic deletions or by a large spectrum of mutations within the elastin gene (6-8) that result in functional haploinsufficiency through either nonsense-mediated decay of mRNA from the mutant allele or the production of a nonfunctional protein (9-11). Williams syndrome (WS), a neurodevelopmental disorder that has SVAS as a component, develops as a consequence of a microdeletion in the chromosomal region 7q11.23 encompassing, among others, the elastin gene $(12,13)$. Narrowing of the ascending aorta is a dominant feature of SVAS (in both the isolated and WS forms), but other arteries, including pulmonary arteries, are often affected. If not corrected, SVAS may lead to increased intracardiac pressure, myocardial hypertrophy, and heart failure.

Recently, we generated mice hemizygous for the elastin gene $\left(\mathrm{Eln}^{+/-}\right)$to study the pathogenic mechanism underlying SVAS $(14,15)$. Characterization of the arterial wall of these mice found that elastin haploinsufficiency results in changes in arterial wall structure, including thinner elastic lamellae and an increased number of SMC layers - changes also observed in humans with SVAS (15). To investigate how these changes influence vascular function, we evaluated a number of basic hemodynamic and mechanical properties of the elastic-conducting vessels of $\mathrm{Eln}^{+/-}$mice. The vascular effects of elastin insufficiency occur early in development and result in a cardiovascular system that has undergone a remarkable adaptation to the altered mechanical properties of the vessel wall. The animals are stably hypertensive with only mild cardiac hypertrophy and do not exhibit the hypertension-induced arterial wall hypertrophy and decreased distensibility of large elastic arteries associated with essential hypertension. The results of this study provide insight into how hemodynamic forces impact vascular development and address the mechanism of hypertension in arteriopathies associated with elastin haploinsufficiency.

\section{Methods}

Animals. Wild-type C57B1/6J mice $\left(\mathrm{Eln}^{+/+}\right)$and mice of matching age (5-7 months) bearing a heterozygous deletion of exon 1 in the elastin gene $\left(E \ln ^{+/-}\right)$backcrossed for more than five generations into the C57B1/6J background (14) were used for all studies. Littermates from $\mathrm{Eln}^{+/}$crosses were used whenever possible. All housing and surgical procedures were in accordance with institutional guidelines.

Surgical procedure and mounting of vessels on the pressure myograph. For vessel mechanical studies, animals were anesthetized by intraperitoneal injection of pentobarbital $(60 \mathrm{mg} / \mathrm{kg})$. A segment of the ascending aorta, the abdominal aorta, the left carotid artery, or the renal artery was quickly excised and placed in a physiological buffer of the following composition: $135 \mathrm{mM} \mathrm{NaCl}$, $5 \mathrm{mM} \mathrm{KCl}, 1.6 \mathrm{mM} \mathrm{CaCl}_{2}, 1.17 \mathrm{mM} \mathrm{MgSO}_{4}, 0.44 \mathrm{mM}$
$\mathrm{KH}_{2} \mathrm{PO}_{4}, 2.6 \mathrm{mM} \mathrm{NaHCO}, 0.34 \mathrm{mM} \mathrm{Na} 2 \mathrm{HPO}_{4}, 5.5$ mM D-glucose, $0.025 \mathrm{mM}$ EDTA, $10 \mathrm{mM}$ HEPES ( $\mathrm{pH}$ 7.4). The vessels were cleaned of adhering connective tissue and fat, then cannulated and mounted onto a pressure arteriograph (Living Systems Instrumentation Inc., Burlington, Vermont, USA, or Danish Myotechnology, Aarhus, Denmark), as described previously (16). The experiments were performed at $37^{\circ} \mathrm{C}$ in an organ bath filled with physiological buffer. Following a 30-minute equilibration period, the vessel was transilluminated under an inverted microscope connected to a charged-coupled device camera and to a computerized system allowing the continuous recording of the vessel diameters.

Except for vessels treated with KCN, all studies used live vessels. Recordings of vessel inner diameters (IDs) and outer diameters (ODs) were taken while increasing the intravascular (transmural) pressure from 0 to 175 $\mathrm{mmHg}$ by steps of $25 \mathrm{mmHg}$ (5 minutes per step). Recordings were also taken while decreasing the pressure following the same steps and timing from 175 to $0 \mathrm{mmHg}$. Assessment of arterial reactivity at $75 \mathrm{mmHg}$ was performed using $5 \mu \mathrm{M}$ phenylephrine (PE) as a SMC-dependent vasoconstrictor (for 10 minutes or until maximum vasoconstriction was reached). This was followed by the addition of the endothelial cell-dependent vasodilator acetylcholine (Ach) $(5 \mu \mathrm{M})$ that was added for 5 minutes or until maximum vasodilatation was reached. The vessel was then bathed at zero pressure in a physiological buffer containing 13 $\mathrm{mM} \mathrm{KCN}$ for 45-60 minutes to poison the vessel wall cells. After verifying at $75 \mathrm{mmHg}$ the nonresponse of the vessel to $5 \mu \mathrm{M} \mathrm{PE}$, the intravascular pressure was raised and lowered as described above while recording the artery segment's ID and OD. For the renal artery, the concentration of PE and Ach used was $1.5 \mu \mathrm{M}$. The bath medium as well as the medium filling the vessel was replaced every 15 minutes.

The thickness of the wall in the large arteries (ascending and abdominal aorta, carotid artery) precluded the localization of the inner wall edge in many transilluminated vessels at pressures lower than $100-125 \mathrm{mmHg}$. Hence, in this pressure range ID could not be measured directly. Above $125 \mathrm{mmHg}$, however, direct measurement of ID was possible because thinning of the arterial wall at high pressure allowed a clear and contrasted image of the inner wall edge. In previous studies, we showed that in both wild-type and elastin-knockout animals, vessel wall cross-sectional area (WCSA) remains relatively constant throughout the experimental pressure range. As a result, ID can be accurately calculated from $\mathrm{OD}$ at any given pressure and from a single measurement of WCSA (16). Thus, when necessary, ID was calculated from the measured OD at the corresponding pressure using values for WCSA calculated from the measurements of OD and ID at $175 \mathrm{mmHg}$.

Circumferential midwall strain, circumferential wall stress, and incremental elastic modulus were calculated according to the formulas given by Gibbons and 
Shadwick (17). Distensibility is defined as the change in relative volume (percentage) of the lumen per pressure unit during a change in intravascular pressure, as described by Smith and Kampine (18). Expression of the distensibility is preferred to the compliance (change in absolute volume per pressure unit) because the difference in initial vessel diameter (at transmural pressure $=0 \mathrm{mmHg}$ ) between $\mathrm{Eln}^{+/+}$and $\mathrm{Eln}^{+/-}$vessels may result in misleading comparisons and interpretations of the difference in the absolute volume. Because the pressure-change increment in our experiments was 25 $\mathrm{mmHg}$, distensibility is expressed as the distensibility per $25 \mathrm{mmHg}$ increment $\left(\mathrm{D}_{25}\right)$.

Heart weight measurements and arterial protein content. The hearts from $11 \mathrm{Eln}^{+/+}$and $11 \mathrm{Eln}^{+/-}$5- to 7-monthold mice were dissected, washed, and weighed (wet weight). The left ventricle and septum weights were obtained using dissected tissue. Ratios of total heart weight to body weight, as well as left ventricle plus septum weight to body weight, were then analyzed.

Vessel segments, $2 \mathrm{~mm}$ long, were used to determine arterial wall protein content ( 20 animals used). For each artery type (ascending and abdominal aorta, carotid artery), six segments from 5- to 7-month-old $\mathrm{Eln}^{+/+}$and $\mathrm{Eln}^{+/-}$genotypes were compared. Desmosine levels were determined by radioimmunoassay (19). Hydroxyproline and total protein content were determined by amino acid analysis using standard techniques (20). Results are expressed as protein mass per vessel segment length (micrograms per millimeter plus or minus SEM).

Blood pressure, heart rate, and physiological measurements. $\mathrm{Eln}^{+/+}$and $\mathrm{Eln}^{+/-}$mice from a range of ages were used for blood pressure and heart rate measurements. The animals were anesthetized using a ketamine/xylazine (87 $\mathrm{mg} / \mathrm{kg}$ and $13 \mathrm{mg} / \mathrm{kg}$, respectively) cocktail and were then restrained on a heated holder to maintain body temperature. A Millar pressure transducer was inserted into the right carotid artery and moved to the aorta where heart rate and systolic and diastolic blood pressure were monitored.

For physiological experiments, the jugular vein of mice was catheterized with PE-10 tubing for fluid infusion, and a Millar pressure transducer was inserted into the right carotid artery for monitoring blood pressure. A series of acute mean arterial pressure responses to a bolus dose of Ang II $(1 \mu \mathrm{g} / \mathrm{kg})$, hexamethonium (5 $\mathrm{mg} / \mathrm{kg})$, candesartan $(100 \mu \mathrm{g} / \mathrm{kg})$, and saralasin (10 $\mu \mathrm{g} / \mathrm{kg}$ ) were evaluated by continuous blood pressure recording. Intravenous infusions were done over a 2.5second period, with compounds dissolved in saline and delivered in a volume of 5-10 $\mu \mathrm{l}$. Isotonic saline was injected as a control.

Plasma renin activity and aldosterone levels in mouse plasma were determined by the clinical laboratories at Barnes Jewish Hospital, Washington University Medical Center (St. Louis, Missouri, USA).

Cardiac output and left-ventricular volume. Animal preparations and image acquisition were performed by echocardiography as described previously (21). Three consecutive cardiac cycles from each of two sequentially acquired cine loops (a total of six frames per animal) were analyzed for end-diastolic and end-systolic left-ventricular volumes. End-diastolic and end-systolic frames of parasternal long-axis images were used for computer-assisted manual tracking of the endocardial border of the left ventricle (LV) chamber. Systolic and diastolic LV volumes (LVVs and LVVd, respectively) were determined by the disk summation method. Stroke volume (LVVd - LVVs) was deduced from these measurements. The values were indexed to the body weight for each animal. Five animals were used in each group.

Immunohistochemical staining with proliferating cell nuclear antigen $\mathrm{Ab}$. Sections from $\mathrm{Eln^{+/+ }}$ and $\mathrm{Eln}^{+/-}$descending aortic tissue fixed in $10 \%$ formalin and embedded in paraffin were incubated with a monoclonal antiproliferating cell nuclear antigen (anti-PCNA) Ab (1:200; BioGenex, San Ramon, California, USA). Primary Ab was visualized by an immunoperoxidase method using the TrueBlue peroxidase substrate according to the manufacturer's instructions.

Statistical analysis. Comparisons of $\mathrm{Eln}^{+/-}$and $\mathrm{Eln}^{+/+}$ body weight, heart weight/body weight ratios, heart rate, systolic, diastolic, and mean systemic blood pressure, total protein, desmosine and hydroxyproline contents (as well as their ratios) in all three vessel types, and vessel diameters (OD and ID) as a function of vasoactive agent treatment were assessed using one- or two-way ANOVA, followed when necessary by Fisher's least significant difference (LSD) test or Student's $t$ test for protein dosages for paired value comparisons.

Vessel diameter as a function of transmural pressure level (0-175 $\mathrm{mmHg}$ ), pressure variation status (increasing or decreasing), $\mathrm{KCN}$ treatment (before or after), and genotype $\left(\mathrm{Eln}^{+/-}\right.$or $\left.E \mathrm{ln}^{+/+}\right)$were compared using a fourway ANOVA followed when necessary by LSD tests for paired value comparisons. Vessel midwall strain, stress, incremental elasticity modulus, distensibility, and local midwall strain comparisons were assessed using the nonparametric Mann-Whitney $U$ test.

Unless otherwise indicated, the results are presented as mean values plus or minus SEM, and $P$ values equal to 0.05 were chosen as the threshold for statistically significant differences.

\section{Results}

Animal weight, blood pressure, heart rate, and heart weight measurements. Comparison of adult $\mathrm{Eln}^{+/-}$and $\mathrm{Eln}^{+/+}$mice revealed a similar average body weight (approximately 32 $\mathrm{g})$, with no statistically significant difference $(P>0.73)$ (Table 1). Systolic, diastolic, and mean blood pressures, however, were substantially higher at all ages in $\mathrm{Eln}^{+/-}$ compared with $\mathrm{Eln}^{+/+}$animals (Table 1). At 6 months of age, mean arterial pressure (MAP) was $96 \pm 5 \mathrm{mmHg}$ in $\mathrm{Eln}^{+/+}$mice and $123 \pm 7 \mathrm{mmHg}$ in $\mathrm{Eln}^{+/-}$mice. This pressure difference was also evident at 7 weeks of age, with MAPs of $92 \mathrm{mmHg}$ and $136 \mathrm{mmHg}$ in the $\mathrm{Eln}^{+/+}$and Eln ${ }^{+/-}$genotypes, respectively. At 15-18 months of age, 


\section{Table 1}

Comparison of body weight, heart rate, blood pressure, heart weight to body weight ratios, cardiac output, and mean wall thickness of 6-month-old $E / n^{+/+}$ and $E / n^{+/-}$mice

\begin{tabular}{|c|c|c|c|}
\hline & $\mathrm{Eln}^{+/+}$ & $\mathrm{Eln}^{+/-}$ & $\begin{array}{c}\text { Difference } \\
\left(E l n^{+/-} \text {versus } E l^{+/+}\right)\end{array}$ \\
\hline BW $(\mathrm{g})$ & $32.0 \pm 0.8$ & $31.6 \pm 1.0$ & ND \\
\hline \multicolumn{4}{|l|}{$\mathrm{BP}(\mathrm{mmHg})$} \\
\hline $\begin{array}{l}\text { Systolic } \\
\text { Diastolic } \\
\text { Mean }\end{array}$ & $\begin{array}{l}121 \pm 6 \\
84 \pm 5 \\
96 \pm 5\end{array}$ & $\begin{array}{l}165 \pm 6 \\
102 \pm 7 \\
123 \pm 7\end{array}$ & $\begin{array}{l}+36 \%^{\mathrm{A}} \\
+21 \%^{\mathrm{A}} \\
+28 \%^{\mathrm{A}}\end{array}$ \\
\hline Heart rate (beats/min) & $351 \pm 27$ & $379 \pm 31$ & ND \\
\hline \multicolumn{4}{|l|}{ Heart weight (\%) } \\
\hline $\begin{array}{l}\text { Total heart weight/BW } \\
(\mathrm{LV}+\text { septum) weight/BW }\end{array}$ & $\begin{array}{l}0.43 \pm 0.01 \\
0.35 \pm 0.01\end{array}$ & $\begin{array}{l}0.50 \pm 0.02 \\
0.40 \pm 0.02\end{array}$ & $\begin{array}{l}+15 \%^{\mathrm{A}} \\
+13 \%^{\mathrm{A}}\end{array}$ \\
\hline \multicolumn{4}{|c|}{$\mathrm{LV}$ and stroke volumes $(\mu \mathrm{l} / \mathrm{g})$ and cardiac output $(\mathrm{ml} / \mathrm{min} / \mathrm{g})$ indexed to BW } \\
\hline $\begin{array}{l}\text { LW diastolic } \\
\text { LV systolic } \\
\text { Stroke volume } \\
\text { Cardiac output }\end{array}$ & $\begin{array}{l}0.80 \pm 0.16 \\
0.23 \pm 0.06 \\
0.57 \pm 0.10 \\
0.37 \pm 0.05\end{array}$ & $\begin{array}{l}1.07 \pm 0.11 \\
0.23 \pm 0.04 \\
0.83 \pm 0.08 \\
0.47 \pm 0.02\end{array}$ & $\begin{array}{l}+34 \%^{\mathrm{A}} \\
\text { ND } \\
+46 \%^{\mathrm{A}} \\
+27 \%^{\mathrm{A}}\end{array}$ \\
\hline \multicolumn{4}{|c|}{ Mean wall thickness $(\mu \mathrm{m})$ at physiological pressure of each genotype } \\
\hline $\begin{array}{l}\text { Ascending aorta } \\
\text { Abdominal aorta } \\
\text { Carotid artery } \\
\text { Renal artery }\end{array}$ & $\begin{array}{l}88.9 \\
76.7 \\
52.5 \\
29.9\end{array}$ & $\begin{array}{l}73.1 \\
57.5 \\
40.5 \\
30.5\end{array}$ & $\begin{array}{c}-18 \%^{\mathrm{A}} \\
-25 \%^{\mathrm{A}} \\
-24 \%^{\mathrm{A}} \\
\text { ND }\end{array}$ \\
\hline
\end{tabular}

ASignificant difference between genotypes $(P \leq 0.05)$. ND, no significant difference. BW, body weight.

MAP remained elevated in the $E n^{+/-}$genotype (144 \pm 4 $\mathrm{mmHg}$ ) compared with wild type (93 $\pm 2 \mathrm{mmHg})$. The pressure difference between the two phenotypes at 6 months of age was confirmed using a tail cuff sphygmomanometer (mean $=121 \mathrm{mmHg}$ for $\mathrm{Eln}^{+/-}$, $86 \mathrm{mmHg}$ for $\left.E \ln ^{+/+}\right)$as well as by femoral artery catheterization $\left(\right.$ mean $=110 \mathrm{mmHg}$ for $\mathrm{Eln}^{+/-}, 84$ $\mathrm{mmHg}$ for $\mathrm{Eln}^{+/+}$). The tail cuff results were from conscious mice and confirm that elevated blood pressure is not a consequence of anesthesia.

No statistically significant difference in heart rate could be detected between the two genotypes (both were in the range of 365 beats per minute in 5- to 7-monthold mice measured under anesthesia). Total heart weight to body weight ratios, as well as LV plus septum to body weight ratios, were higher $(15 \%$ and $13 \%$, respectively) in $E l^{+/-}$than in $E l^{+/+}$animals (Table 1).

$L V$ volume and cardiac output. End-diastolic LV volume indexed to body weight (LVVdI) was increased in $\mathrm{Eln}^{+/}$ mice, while end-systolic LV volume (LVVsI) was not significantly different between the $\mathrm{Eln}^{+/-}$and control animals. Consequently, stroke volume was significantly increased and, even in the presence of slightly decreased heart rate, cardiac output indexed to body weight was significantly increased in $\mathrm{Eln}^{+/-}$mice (Table 1).

Elastin and collagen changes in the wall of large arteries of $E n^{+/-}$mice. We noted previously that elastic lamellae were thinner in $\mathrm{Eln}^{+/-}$mice and that elastin mRNA levels were decreased in the arterial wall (15). To determine how these differences translate to changes in total elastin content, elastin concentration in arterial segments was determined by quantifying desmosine (a crosslinking amino acid unique to elastin) following protein hydrol- ysis. In a similar way, hydroxyproline levels were used to quantify total collagen.

When protein levels are expressed as protein content per millimeter of vessel, total protein values were found to be significantly higher in the ascending and abdominal aortas of $\mathrm{Eln}^{+/+}$ mice than in similar segments from the $E \mathrm{ln}^{+/-}$ genotype. There is no difference in total protein content in the carotid artery from either animal group (Table 2). Within each genotype, the total protein, desmosine, and hydroxyproline content differed between vessel types (ascending aorta > abdominal aorta > carotid artery), which reflects known differences in wall mass and elastic properties of the vessel segments. Desmosine levels per millimeter of vessel were lower by $34-49 \%$ in $\mathrm{Eln}^{+/-}$compared with $\mathrm{Eln}^{+/+}$mice in the three vessels studied. Hydroxyproline levels per millimeter of vessel, indicative of collagen content, were found to be significantly lower in the ascending aorta $(-24 \%)$ of $E \ln ^{+/-}$animals than in $\mathrm{Eln}^{+/+}$ mice, whereas no difference was detected between the other two vessels (Table 2).

To better understand the functional significance of differences in collagen and elastin levels, both measurements were normalized to the total protein content of the vessel wall to provide an indication of the local matrix composition. In all three vessel types, the level of elastin as a percentage of total protein (desmosine/total protein) was lower by approximately $35 \%$ in $\mathrm{Eln}^{+/-}$compared with $\mathrm{Eln}^{+/+}$animals. Interesting$1 y$, there was no statistically significant difference in the ratio of collagen to total protein (hydroxyproline/total protein) when the three vessel types from the two animal groups were compared, suggesting that relative collagen synthesis and accumulation was unchanged. Expression of elastin as a ratio to collagen levels (desmosine/hydroxyproline) confirms that there is more collagen relative to elastin in $\mathrm{Eln}^{+/-}$vessels. As expected, the desmosine/hydroxyproline ratio is higher in the more

\section{Table 2}

Total protein, elastin, and collagen arterial wall content in El/ ${ }^{+/+}$versus $E / n^{+/-}$mice

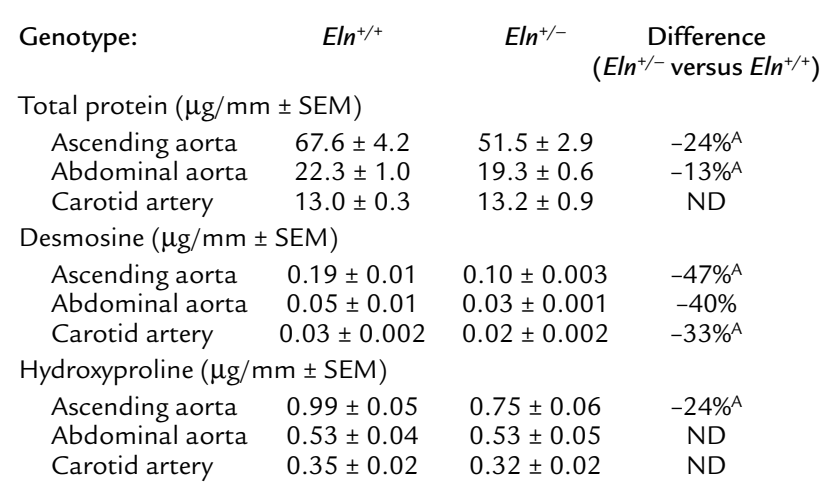

ASignificant difference between genotypes calculated using two-way ANOVA $(P \leq 0.05) . n=6$ animals for each measurement. 

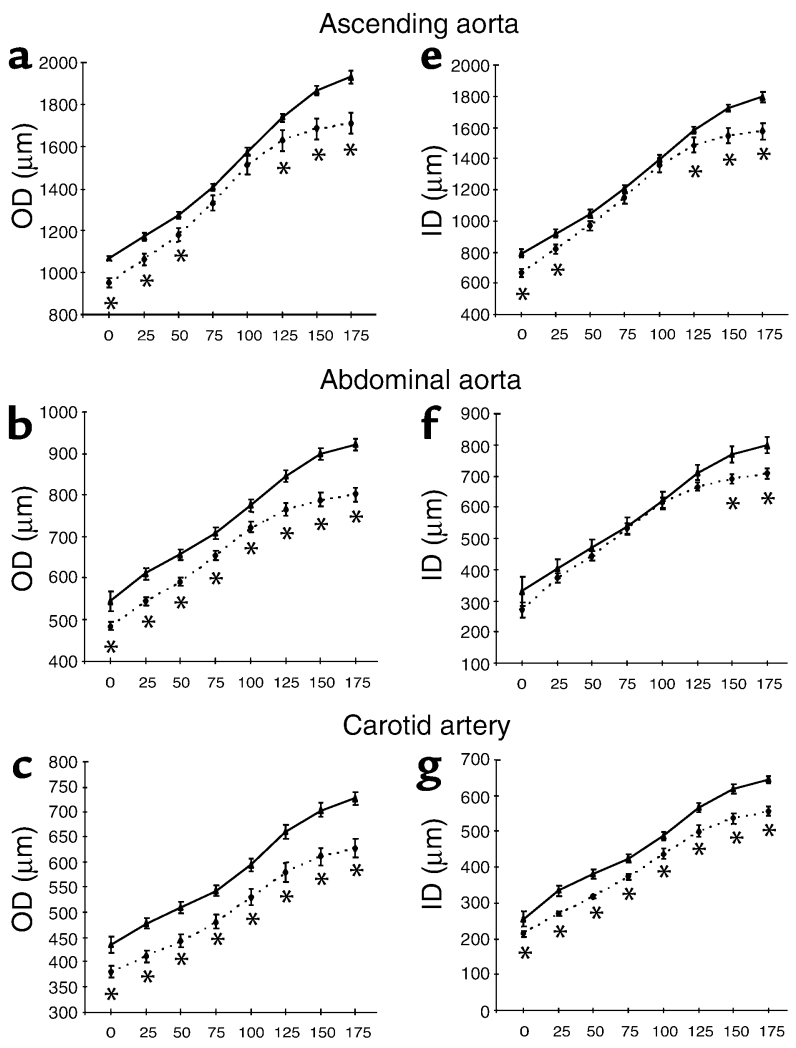

arotid artery

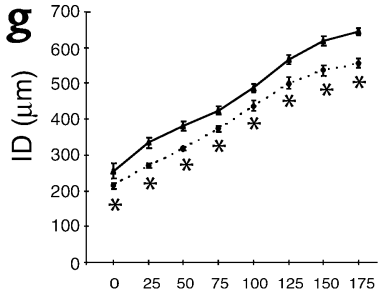

Renal artery
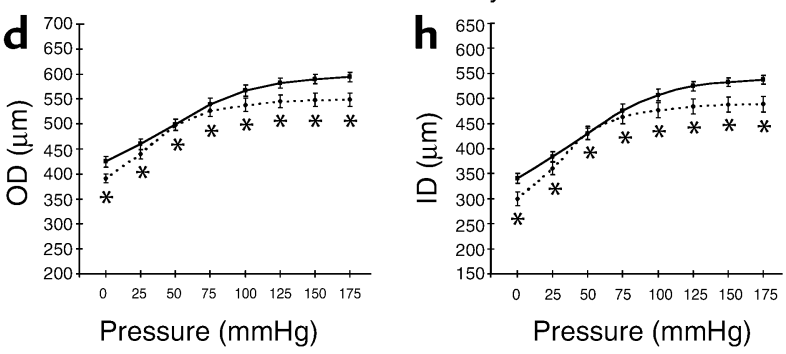

\section{Figure 1}

Pressure-diameter relationships for segments of arteries from $\mathrm{Eln}^{+/+}$ and $\mathrm{E} / \mathrm{n}^{+/-}$mice. Pressure-OD curve in the ascending aorta (a), in the abdominal aorta (b), in the carotid artery (c), and in the renal artery (d). Pressure-ID curve in the ascending aorta (e), in the abdominal aorta $(\mathbf{f})$, in the carotid artery $(\mathbf{g})$, and in the renal artery $(\mathbf{h}) .{ }^{*}$ Significant difference ( $P \leq 0.05$, LSD test) between $\mathrm{E} / \mathrm{n}^{+/+}$and $\mathrm{E} / \mathrm{n}^{+/-}$vessel diameters at the corresponding pressure. Mean values \pm SEM, $n=4-8$ for each vessel type. Solid lines, Eln ${ }^{+/+}$; dotted lines, El $n^{+/-}$.

elastic ascending aorta than in the abdominal aorta and the carotid artery in both phenotypes. A table with ratios of desmosine and hydroxyproline to total protein and ratios of desmosine to hydroxyproline for the ascending and abdominal aorta and the carotid artery is supplied in the supplementary online material (http://www.jci.org/cgi/content/full/112/9/1419/DC1).

Mechanical properties of arteries. The mechanical properties of the ascending aorta, abdominal aorta, carotid artery, and renal artery of $\mathrm{Eln}^{+/-}$and $\mathrm{Eln}^{+/+}$mice were studied by correlating changes in vessel ID and OD with alterations in transmural pressure. To determine the relative cellular and noncellular contributions to compli- ance of the elastic arteries, vessels from $\mathrm{Eln}^{+/-}$and $\mathrm{Eln}^{+/+}$ mice were studied before and after poisoning cells with $\mathrm{KCN}$. In the three large arteries studied (ascending and abdominal aorta and carotid artery), vascular diameter changed by only a few percent following $\mathrm{KCN}$ treatment (data not shown). This is consistent with the findings of others showing that muscle contributes little to the mechanical properties of large arteries $(22,23)$. The same minimal effect of $\mathrm{KCN}$ on the arterial diameter is observed in the smaller renal artery.

The ODs of $\mathrm{Eln}^{+/-}$arteries were significantly smaller than $E n^{+/+}$arteries at any given pressure over the entire range of pressure studied (Figure 1, a-d), except in the ascending aorta where no statistically significant difference could be detected at 75 and $100 \mathrm{mmHg}$ (Figure 1a). In all four vessel types, the $\mathrm{Eln}^{+/-}$and $\mathrm{Eln}^{+/+}$ODs showed the greatest divergence at high transmural pressure (125-175 mmHg) (Figure 1, a-d). Similar to ODs, the IDs of vessels in $\mathrm{Eln}^{+/-}$animals were smaller than those in $\mathrm{Eln}^{+/+}$mice and showed the greatest divergence at high and low transmural pressure (Figure 1, e-h) (16). Wall thickness for the $E h^{+/-}$aorta and carotid artery was $20-25 \%$ less than $E \mathrm{ln}^{+/+}$vessels at the physiological MAP of each genotype, whereas no difference between genotype was detected in the renal artery (Table 1).

Calculations of distensibility $\left(\mathrm{D}_{25}\right)$ indicate that large arteries in $\mathrm{Eln}^{+/-}$mice undergo greater dilation at transmural pressures below $100 \mathrm{mmHg}$ than do arteries from $E h^{+/+}$mice. The opposite occurs at high transmural pressures (above $100 \mathrm{mmHg}$ ), where $\mathrm{Eln}^{+/+}$animals show higher distensibility than arteries from $\mathrm{Eln}^{+/-}$mice (Figure 2, a-c). Wall stress, in contrast, does not differ between $\mathrm{Eln}^{+/-}$and $\mathrm{Eln}^{+/+}$vessels at any given pressure over the tested pressure range $(0-175 \mathrm{mmHg})$. At the physiological MAP of $100 \mathrm{mmHg}$ in $\mathrm{Eln}^{+/+}$and $125 \mathrm{mmHg}$ in $\mathrm{Eln}^{+/-}$animals, however, wall stress is found to be significantly higher in $\mathrm{Eln}^{+/-}$than in $\mathrm{Eln}^{+/+}$ arteries in all three vessel types.

The arterial midwall strain was lower in $\mathrm{En}^{+/+} \mathrm{com}-$ pared with $E n^{+/-}$mice in the ascending and abdominal aorta between $25-50$ and $125 \mathrm{mmHg}$. Interestingly, no difference in midwall strain could be detected at any pressure in the carotid artery in a comparison of the two animal groups. In all three vessel types and in both genotypes, a similar maximum midwall strain close to 1 was measured at $175 \mathrm{mmHg}$, corresponding to a doubling of the diameter seen at ambient pressure. When comparisons were made at physiological MAP for the two animal groups, however, the arterial midwall strain in $E \ln ^{+/+}$mice was lower than the midwall strain in $E n^{+/-}$vessels. This is true for all three types of vessels. At similar midwall strain, the arterial wall stress is generally lower in vessels from $\mathrm{Eln}^{+/-}$mice than in the $\mathrm{Eln}^{+/+}$ arteries, with the possible exception of the carotid artery where the differences are small. When the data are analyzed in terms of incremental elastic modulus indicative of the vessel wall stiffness, there are no differences between animal groups in the pressure range of $0-125 \mathrm{mmHg}$. At higher pressures where collagen 

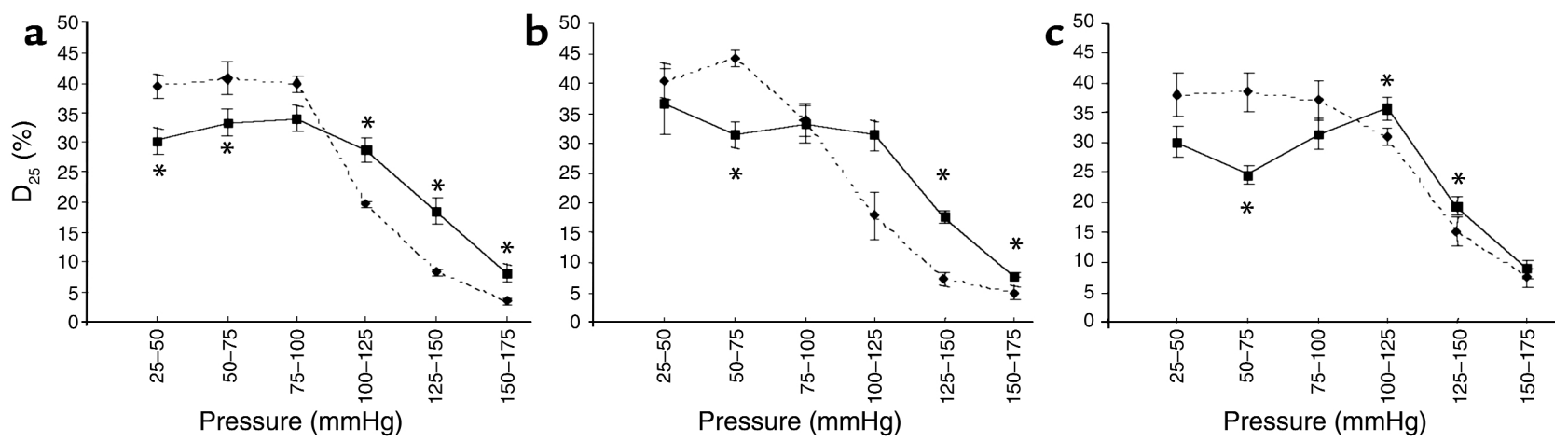

Figure 2

Distensibility of $E / n^{+/+}$and $E / n^{+/-}$aorta and carotid artery. Distensibility $\left(\mathrm{D}_{25}\right)$ of the ascending aorta (a), abdominal aorta (b), and carotid artery $(\mathbf{c})$. ${ }^{*}$ Significant difference $(P \leq 0.05, U$ test $)$ between $E / n^{+/+}$and $E / n^{+/-}$vessels. Mean values \pm SEM, $n=4-8$ for each vessel type. Solid lines, $E \mathrm{~h}^{+/+}$; dotted lines, $E / n^{+/-}$.

bears an increasing fraction of the stress, the incremental elastic modulus is higher in ascending and abdominal aortas from $\mathrm{Eln}^{+/-}$mice, whereas differences in the elastic modulus in the carotid artery are minimal. A graph showing stress, strain, and incremental elastic modulus of the $\mathrm{Eln}^{+/+}$and $\mathrm{Eln}^{+/-}$ascending and abdominal aorta and carotid artery is available in the supplementary online material (http://www.jci.org/ cgi/content/full/112/9/1419/DC1).

Ex vivo response of elastic artery segments to vasoactive agents. Artery segments from 5- to 7-month-old $\mathrm{Eln}^{+/+}$ and $E n^{+/-}$mice undergo normal vasoconstriction in response to $\mathrm{PE}$ and normal vasodilatation in response to Ach (Figure 3, a-d). There was no difference in responsiveness to $5 \mu \mathrm{MPE}$ between $\mathrm{Eln}^{+/-}$and $\mathrm{Eln}^{+/+}$vessels in the ascending aorta and carotid artery (approximately $30 \%$ vasoconstriction), and all four vessels from both mouse genotypes reacted similarly to $5 \mu \mathrm{M}$ Ach. The $E \ln ^{+/-}$abdominal aorta showed a significantly greater response to $\mathrm{PE}$, when compared with the wildtype counterpart (Figure 3b), similar to the increased response of the $E \ln ^{+/-}$renal artery (Figure 3d).

Vascular physiology, reactivity, and proliferation studies. To determine whether the functionality of resistance vessels is adversely affected by elastin haploinsufficiency and to explore the fundamental mechanism of hypertension in these animals, we per-

\section{Figure 3}

Reactivity of artery segments. Effect of PE and Ach (5 $\mu \mathrm{M}$, except for the renal artery, which is $1.5 \mu \mathrm{M}$ ) on the ID of the ascending aorta (a), the abdominal aorta (b), the carotid artery (c), and the renal artery (d). Control is untreated vessel. Values for the $\mathrm{E} / \mathrm{n}^{+/-}$vessel have been normalized to $E / n^{+/+}$control. *Significant difference ( $P \leq 0.05$, LSD test) between $E / n^{+/+}$and $E / n^{+/-}$ vessel responsiveness. "Significant difference $(P \leq 0.05$, LSD test) from the corresponding control vessel. Mean values \pm SEM, $n=4-8$ for each vessel type. Gray bars, $\mathrm{Eln}^{+++}$; white bars, $\mathrm{Eln}{ }^{+/-}$. formed several types of pharmacological experiments with anesthetized mice. Both wild-type and $\mathrm{Eln}^{+/-}$mice displayed a similar increase in blood pressure in response to a maximal pressor dose of Ang II (Figure 4a). Blocking ganglionic transmission with hexamethonium, an inhibitor of nicotinic channels, had little effect on MAP of wild-type or $E l^{+/-}$mice (data not shown), suggesting that increased vascular tone is not resulting from neurotransmitter signaling. We found, however, that infusion of the Ang I receptor antagonists candesartan and saralasin into the $\mathrm{Eln}^{+/-}$mice caused a dramatic decrease in blood pressure (Figure $4 \mathrm{~b}$ ), reaching MAP levels slightly below the baseline of wild-type animals but still higher than the MAP of wild-type animals treated with candesartan. In wildtype mice, saralasin had a slight and transient agonist effect but had no lasting influence on MAP.

Measurement of plasma renin activity found a greater than twofold increase in $E \mathrm{ln}^{+/-}$mice compared with controls $\left(22.5 \pm 16.9 \mathrm{ng} / \mathrm{ml} / \mathrm{h}\right.$ for $E n^{+/+}$compared with $55.9 \pm 16 \mathrm{ng} / \mathrm{ml} / \mathrm{h}$ of $E \ln ^{+/-}$animals). Interestingly, aldosterone levels were equivalent for both genotypes
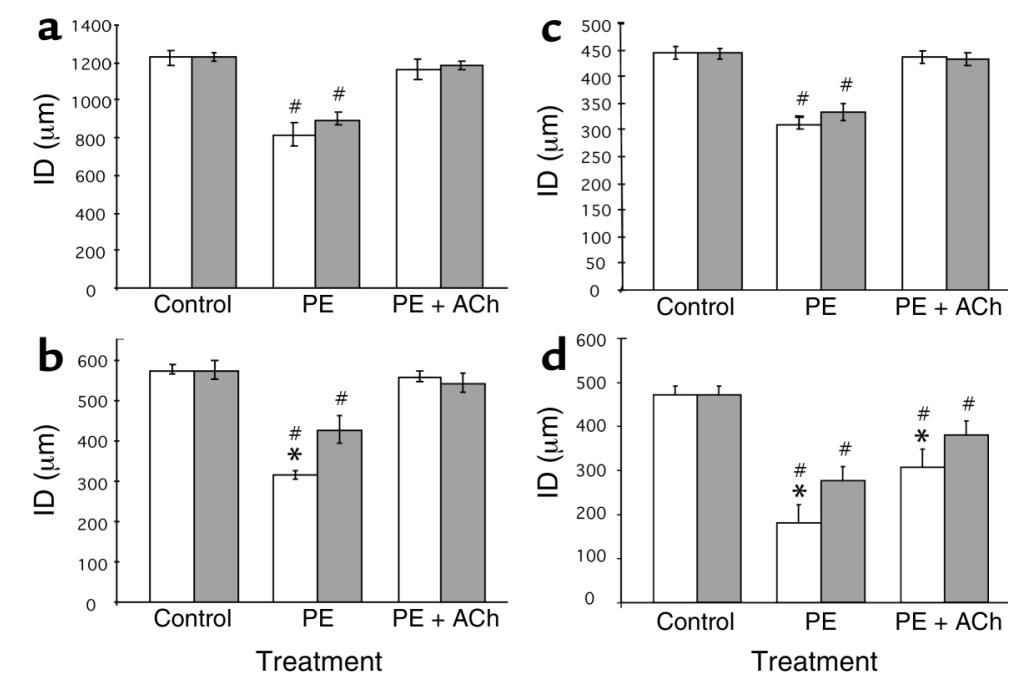


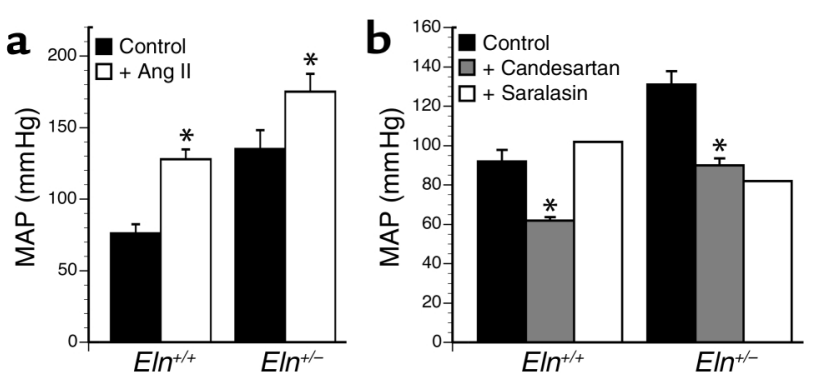

Figure 4

Alteration in MAP after intravenous injection of Ang II or Ang I receptor antagonists. (a) Maximal change in MAP in response to a bolus dose $\left(1 \mu \mathrm{g} / \mathrm{kg}\right.$ i.v.; $n=8$ for $E \mathrm{n}^{+/+}, n=3$ for $\left.E / n^{+/-}\right)$of Ang II. (b) Blood pressure change in response to infusion of saralasin $(10 \mu \mathrm{g} / \mathrm{kg} ; n=2$ for each phenotype $)$ and candesartan $\left(100 \mu \mathrm{g} / \mathrm{kg} ; n=3\right.$ for $\mathrm{E}^{+/ /+}, n=5$ for $\left.E / n^{+/-}\right)$. Error bars show SEM. *Significant difference $(P \leq 0.05$, $t$ test) between treated and control vessels within each genotype.

$\left(272.4 \pm 86 \mathrm{pg} / \mathrm{ml}\right.$ for $\mathrm{Eln}^{+/+}, n=7$, and $307.0 \pm 140$ $\mathrm{pg} / \mathrm{ml}$ for $E l^{+/-}, n=6$ ).

No PCNA-positive cells were detected in the media of either $\mathrm{Eln}^{+/+}$or $E \mathrm{ln}^{+/-}$6-month-old mice (data not shown). PCNA-positive cells, however, could be readily identified in vascular tissue of newborn mice, which served as a positive control for PCNA staining (data not shown).

\section{Discussion}

The high blood pressure associated with the $\mathrm{Eln}^{+/-}$ genotype is consistent with systemic hypertension that is a frequent complication of SVAS and WS, diseases of elastin haploinsufficiency in humans (24-26). MAP is $30-40 \%$ higher in $\mathrm{Eln}^{+/-}$mice than control animals, a trait that shows complete penetrance in the $\mathrm{Eln}^{+/-}$genotype. In humans, the incidence of hypertension is less than the complete penetrance we observe in mice. In WS, for example, approximately $80 \%$ of affected individuals have clinically apparent SVAS (27) and 40-60\% have documented arterial hypertension $(24-26,28)$. For reasons not yet understood, the incidence of hypertension in isolated SVAS is much lower. Of the two forms of SVAS, the hemizygosity of the elastin gene in WS is genetically most like the $\mathrm{Eln}^{+/-}$mouse.

The association of hypertension with elastin haploinsufficiency strongly suggests that vessel wall proteins, particularly elastin, should be considered as causal genes for essential hypertension. Any factor that reduces elastin protein concentration or alters vessel compliance during a critical window of vessel wall formation could have a modifying effect on the progression of, or susceptibility to, hypertension or other vascular diseases. This could include mutations within any of the other genes that participate in elastic fiber assembly or perhaps polymorphisms within the elastin gene itself. Secondary factors could also impact elastin deposition and vascular function. There is evidence, for example, that people who had low birth weight tend to have higher blood pressure in later life. The authors of these studies argue that fetuses whose growth is impaired synthesize less elastin in the aorta and large arteries and that this deficiency leads to changes that could predispose an individual to higher blood pressure $(29,30)$. There is also evidence that maternal and postnatal vitamin $\mathrm{D}$ ingestion lowers aortic elastin content (vitamin D is known to downregulate elastin production in cultured cells) and alters vascular compliance similar to that which is seen in our mice (31). Taken together, these studies suggest that environmental or nutritional factors could impact directly vascular development or might act as modifiers on phenotypes involving elastin gene mutations or polymorphisms.

In a previous study, we noted thinner elastic lamellae and decreased elastin mRNA levels in the arterial wall of $E l n^{+/-}$mice (15). Quantitation of desmosine levels as an index of elastin protein confirmed what was predicted by these earlier findings, namely, that elastin protein is significantly reduced in the $\mathrm{Eln}^{+/-}$animals. When normalized to total protein, our findings show that elastin levels are approximately $35 \%$ lower in the ascending, abdominal, and carotid arteries from $\mathrm{Eln}^{+/-}$ mice. The ratio of collagen to total protein was identical in both genotypes, indicating that relative collagen synthesis and accumulation is unchanged.

The decreased elastin to collagen ratio suggests that arteries in the $\mathrm{Eln}^{+/-}$mouse should be stiffer than their wild-type counterparts. This was confirmed through mechanical studies that documented a difference in vessel distensibility between the two genotypes (Figures 1 and 2). In our initial studies, we reported that the aorta from $\mathrm{Eln}^{+/+}$and $E \mathrm{hl}^{+/-}$mice had similar extensibilities at a presumed physiologic pressure of 100 $\mathrm{mmHg}(15)$. The dramatic difference in blood pressure

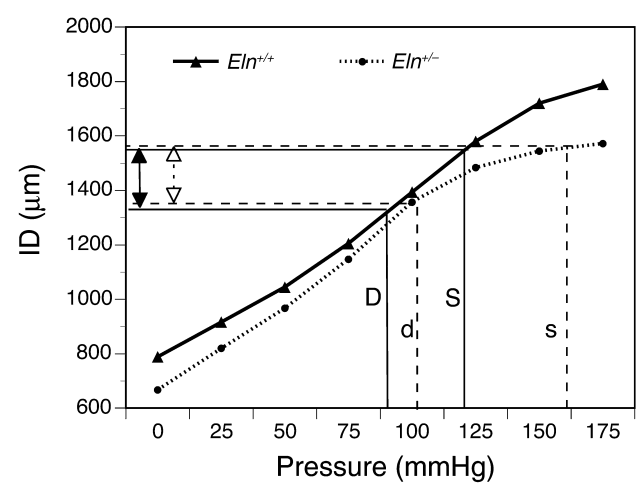

Figure 5

Vascular IDs are similar at physiological blood pressures of $E / n^{+/-}$and $\mathrm{Eln^{+/+ }}$ genotypes. Comparison of ascending aorta IDs of $\mathrm{Eln^{+/+ }}$ and $E / n^{+/-}$mice at their respective physiological pressures shows that the vessel in $E / n^{+/-}$animals is smaller at every intravascular pressure. Because the basal blood pressure in the Eln ${ }^{+/-}$genotype is higher, however, its effective working diameter (open arrows) is comparable to that of the wild-type animal (filled arrows). Solid lines show the working diameter of the wild-type artery at its physiological systolic (S) and diastolic (D) pressures (120/80). Dotted lines show that the systolic (s) and diastolic (d) dimensions of the $E / n^{+/-}$artery at its higher pressures $(160 / 105)$ are similar to the wild-type values. 
between the two genotypes, however, alters our interpretation of the earlier physiological findings. At their higher physiological pressure (and above), $\ln ^{+/-}$vessels are stiffer and have a higher circumferential wall stress, circumferential wall strain, and incremental elasticity modulus than vessels from $E \ln ^{+/+}$animals. At lower pressures, however, $E \ln ^{+/-}$vessels are more elastic and show greater dilation than do arteries from wild-type mice. Similar changes in vessel compliance have been reported in humans with WS. Using noninvasive ultrasound, Salaymeh and Banerjee found that children with WS have a stiffer aorta and a less-compliant systemic arterial bed (28). Interestingly, a similar study found that the compliance of the carotid artery is not modified in WS, even though increased intima-media thickness and lower arterial stiffness were consistent features (32). Despite the structural alterations in the $\mathrm{Eln}^{+/-}$vessel wall, no significant change in the functional potential of the vascular cells was detected. Vessels from $\mathrm{Eln}^{+/-}$mice responded appropriately and to the same extent as $E \ln ^{+/+}$vessels to both vasodilators and vasoconstrictors.

A major difference between the human pathology associated with SVAS and that seen in $\mathrm{Eln}^{+/-}$mice is that humans, but not mice, develop severe localized aortic occlusion due to subendothelial SMC proliferation. A possible explanation for this difference may relate to the higher vascular wall stress in humans compared with mice, due to their larger size. Higher circumferential wall stress could make vessels more prone to pressurerelated damage, leading to stenosis. It is important to note that at their higher physiological pressures, $\mathrm{Eln}^{+/-}$ vessels are working close to their maximum strain, suggesting that these animals may be more prone to develop hypertensive cardiovascular pathologies when stressed, since their vessels have a lower potential for distension if the blood pressure increases.

The smaller ID of the large elastic arteries coupled with increased arterial stiffness and elevated cardiac output is predicted to be disadvantageous to cardiac function. Under normal circumstances, this should lead to cardiac hypertrophy, circulatory dysfunction, and possibly death. When we analyzed the hearts of 6month-old $\mathrm{Eln}^{+/-}$animals, we observed that the total heart weight as well as the LV weight was increased by $15 \%$ and $13 \%$, respectively, over wild-type controls. It is therefore somewhat of a paradox that the $\mathrm{Eln}^{+/-}$animals have a normal life span, exhibit no overt signs of degenerative cardiovascular disease, and show none of the adverse effects observed with other animal models of induced or spontaneous hypertension $(33,34)$. One explanation for the normal characteristics of the $\mathrm{Eln}^{+/-}$ mouse is that the elevated blood pressure is an important adaptive response for maintaining cardiovascular function. Figure 5 shows that at the higher systemic physiological pressure of the $E \mathrm{ln}^{+/-}$mouse, the effective working ID of the ascending aorta, is comparable to that of the wild-type animal. Because the functional demands of the organism require that normal perfu- sion be preserved, the adjustment of vessel ID through an increase in blood pressure could be a necessary adaptation to maintain vessel patency appropriate to accommodate cardiac output and perfusion.

While we cannot completely exclude structural alterations in the microvasculature as being responsible for hypertension in the $\mathrm{Eln}^{+/-}$mice, pharmacological studies with vasoactive agents suggested that vascular dysfunction secondary to hypertrophy of the resistance vasculature is not the main cause of the hypertensive phenotype. Compared with wild-type controls, $\mathrm{Eln}^{+/-}$ mice displayed an equivalent increase in blood pressure in response to a maximal dose of Ang II and an equivalent decrease in blood pressure after infusion of candesartan (Figure 4). In both cases, however, the difference in MAP between wild-type and $E l^{+/-}$animals persisted at each end point.

The change in blood pressure seen in the $E \mathrm{In}^{+/-}$but not $\mathrm{Eln}^{+/+}$animals in response to saralasin was of particular interest because in both human and animal studies, saralasin infusion reliably identifies an Ang pressor response associated with high renin forms of hypertension (35-37). Our finding of elevated renin activity in plasma of $\mathrm{Eln}^{+/-}$mice is consistent with high renin levels predicted by saralasin inhibition. The equivalent effects of saralasin, a nonselective Ang II receptor antagonist, and candesartan, an antagonist specific for the Ang I receptor, indicates that blood pressure elevation is occurring through the Ang I receptor. Taken together, the Ang II receptor inhibitor studies and high plasma renin levels suggest a role for the kidney and the renin-angiotensin system (RAS) in maintaining high blood pressure in $\mathrm{Eln}^{+/-}$mice. Increased cardiac stroke volume and cardiac output in $E l n^{+/-}$animals are also consistent with the activation of the RAS and indicate expansion of the intravascular volume and increased contractility of the myocardium. It is interesting that aldosterone levels are equivalent in the two genotypes, confirming that the mechanism underlying the hypertension in the $E n^{+/-}$mouse is not permanently mediated by actions of this important hormone.

In a previous study we speculated that the increased number of lamellar units in the arterial wall of SVAS individuals and in $\mathrm{Eln}^{+/-}$mice arose during vascular development in response to altered wall stress (15). A role for hemodynamics in vessel wall development (38, $39)$ and in modulating elastin production $(40,41)$ has been suggested from numerous studies of vascular remodeling in response to altered pressure and flow. In the developing chick coronary artery, for example, SMC recruitment from undifferentiated mesenchyme does not occur until the connection to the aorta is made and actual blood flow through these vessels has begun (42). When the vessel wall is forming, SMC differentiation, lamellar number, and elastin content coordinately increase with the gradual rise in blood pressure until the proper number of lamellar units are organized (43, 44). The relatively constant tension per lamellar unit 
and their uniformity of composition, regardless of species, indicate that the proportion of collagen, elastin, and SMCs in the media is optimal for the stresses to which the aorta is subjected (1). This is why the increased number of elastic lamellae in the arterial wall of $\mathrm{Eln}^{+/-}$mice is unique.

Many studies in mature organisms have shown that the response of fully developed blood vessels to hemodynamic stress is clearly different from what we have documented in $\mathrm{Eln}^{+/-}$mice. In spontaneous or essential hypertension in humans and in experimental hypertension in animals $(33,34)$, vessel walls become thickened through cellular maturation and increased matrix deposition, but there is no change in lamellar number (38, $39,42,45)$. The reason that fetal and mature vascular wall cells respond differently to hemodynamic stress may reflect the effects of the extensive matrix found in older vessels. Because there is more elastin in the mature vessel wall, the ECM plays a greater role in accommodating wall stress than in earlier developmental stages. Hence, the most efficient adaptive mechanism for a mature vessel to use to deal with changes in pressure is that of altering the amount of the load-bearing ECM. In elastin insufficiency, however, SMCs cannot make sufficient elastin, and the increased number of smooth muscle layers (i.e., lamellar units) may be an attempt by the cells to normalize wall stress. We know that the increase in lamellar number is established at the time of birth (15) and that elevated blood pressure can be documented in neonatal $\mathrm{Eln}^{+/-}$mice as early as pressure measurements can be obtained, suggesting that alterations in $\mathrm{Eln}^{+/-}$vessel wall structure and hemodynamics occur early in formation of the arterial wall. The changes found in the $E \mathrm{In}^{+/-}$arterial wall suggest that presumptive vascular SMCs are capable of altering vessel wall structure by sensing and responding to wall stress and that mechanical forces play an important role in determining lamellar number. Elucidation of cellular mechanisms for sensing mechanical signals will have important implications for understanding vascular development generally as well as furthering our understanding of vascular pathology in elastin-related human genetic diseases such as SVAS, WS, and hypertension in general.

\section{Acknowledgments}

We thank Douglas Taylor (University of Utah), Gail Maher, Carla J. Weinheimer, and Michael Courtois (Washington University) for technical assistance. This work was funded by postdoctoral fellowship grants from the Fondation pour la Recherche Médicale (France) and the American Heart Association - Missouri affiliate to G. Faury; by grants from the NIH to R.P. Mecham (HL-53325 and HL-62295), to R.P. Mecham and D.P. Kelly (HL-61001), and to W.A. Boyle (GM-55849); and from the Association Française contre les Myopathies (France) and the European Union (Fifth framework programme research project "Towards the maintenance of tissue elasticity for healthy aging" [TELASTAR], contract no. QLK6-CT-2001-00332) to G. Faury. Funds were also provided by a grant from the National Marfan Foundation to R.P. Mecham.

1. Wolinsky, H., and Glagov, S. 1967. A lamellar unit of aortic medial structure and function in mammals. Circ. Res. 20:99-111.

2. Leung, D.Y.M., Glagov, S., and Mathews, M.B. 1977. Elastin and collagen accumulation in rabbit ascending aorta and pulmonary trunk during postnatal growth: correlation of cellular synthetic response with medial tension. Circ. Res. 41:316-323.

3. Clark, J.M., and Glagov, S. 1985. Transmural organization of the arterial media. The lamellar unit revisited. Arteriosclerosis. 5:19-34.

4. Tassabehji, M., et al. 1998. An elastin gene mutation producing abnormal tropoelastin and abnormal elastic fibres in a patient with autosomal dominant cutis laxa. Hum. Mol. Gen. 7:1021-1028.

5. Zhang, M.C., et al. 1999. Cutis laxa arising from frameshift mutations in exon 30 of the elastin gene (ELN). J. Biol. Chem. 274:981-986.

6. Curran, M.E., et al. 1993. The elastin gene is disrupted by a translocation associated with supravalvular aortic-stenosis. Cell. 73:159-168.

7. Ewart, A.K., Jin, W.S., Atkinson, D., Morris, C.A., and Keating, M.T. 1994. Supravalvular aortic stenosis associated with a deletion disrupting the elastin gene. J. Clin. Invest. 93:1071-1077.

8. Li, D.Y., et al. 1997. Elastin point mutations cause an obstructive vascular disease, supravalvular aortic stenosis. Hum. Mol. Gen. 6:1021-1028.

9. Urbán, Z., et al. 1999. Supravalvular aortic stenosis: a splice site mutation within the elastin gene results in reduced expression of two aberrantly spliced transcripts. Hum. Genet. 104:135-142.

10. Urbán, Z., et al. 2000. Isolated supravalvular aortic stenosis; functional haploinsufficiency of the elastin gene as a result of nonsense-mediated decay. Hum. Genet. 106:577-588.

11. Kozel, B.A., Wachi, H., Davis, E.C., and Mecham, R.P. 2003. Domains in tropoelastin that mediate elastin deposition in vitro and in vivo. J. Biol. Chem. 278:18491-18498.

12. Ewart, A.K., et al. 1993. Hemizygosity at the elastin locus in a developmental disorder, Williams syndrome. Nat. Genet. 5:11-16.

13. Morris, C.A., and Mervis, C.B. 2000. Williams syndrome and related disorders. Annu. Rev. Genomics Hum. Genet. 1:461-484.

14. Li, D.Y., et al. 1998. Elastin is an essential determinant of arterial morphogenesis. Nature. 393:276-280.

15. Li, D.Y., et al. 1998. Novel arterial pathology in mice and humans hemizygous for elastin. J. Clin. Invest. 102:1783-1787.

16. Faury, G., et al. 1999. Relation between outer and luminal diameter in cannulated arteries. Am. J. Physiol. 277:H1745-H1753.

17. Gibbons, C.A., and Shadwick, R.E. 1989. Functional similarities in the mechanical design of the aorta in lower vertebrates and mammals. Experientia. 45:1083-1088.

18. Smith, J.J., and Kampine, J.P. 1990. Circulatory physiology - The essentials. 3rd edition. Williams \& Wilkins. Baltimore, Maryland, USA. 345 pp.

19. Starcher, B., and Conrad, M. 1995. A role for neutrophil elastase in the progression of solar elastosis. Connect. Tissue Res. 31:133-140.

20. Brown-Augsburger, P., Tisdale, C., Broekelmann, T., Sloan, C., and Mecham, R.P. 1995. Identification of an elastin cross-linking domain that joins three peptide chains: possible role in nucleated assembly. J. Biol. Chem. 270:17778-17783.

21. Rogers, J., et al. 1999. RGS4 causes increased mortality and reduced cardiac hypertrophy in response to pressure overload. J. Clin. Invest. 104:567-576

22. Torrance, H.B., and Shwatz, S. 1961. The elastic behaviour of the arterial wall. J. R. Coll. Surg. Edinb. 7:55-60.

23. Berry, C.L., Greenwald, S.E., and Rivett, J.F. 1975. Static mechanical properties of the developing and mature rat aorta. Cardiovasc. Res. 9:669-678.

24. Broder, K., et al. 1999. Elevated ambulatory blood pressure in 20 subjects with Williams syndrome. Am J. Med. Genet. 83:356-360.

25. Rose, C., Wessel, A., Pankau, R., Partsch, C.-J., and Bürsch, J. 2001. Anomalies of the abdominal aorta in Williams-Beuren syndrome another cause of arterial hypertension. Eur. J. Pediatr. 160:655-658.

26. Eronen, M., et al. 2002. Cardiovascular manifestations in 75 patients with Williams syndrome. J. Med. Genet. 39:554-558.

27. Lowery, M.C., et al. 1995. Strong correlation of elastin deletions, detected by FISH, with Williams syndrome: evaluation of 235 patients. Am. J. Hum. Genet. 57:49-53.

28. Salaymeh, K.J., and Banerjee, A. 2001. Evaluation of arterial stiffness in children with Williams syndrome: does it play a role in evolving hypertension? Am. Heart J. 142:549-555.

29. Martyn, C.N., et al. 1995. Growth in utero, adult blood pressure, and arterial compliance. Br. Heart J. 73:116-121.

30. Martyn, C.N., and Greenwald, S.E. 1997. Impaired synthesis of elastin in walls of aorta and large conduit arteries during early development 
as an initiating event in pathogenesis of systemic hypertension. Lancet. 350:953-955

31. Norman, P., Moss, I., Sian, M., Gosling, M., and Powell, J. 2002. Maternal and postnatal vitamin $D$ ingestion influences rat aortic structure, function and elastin content. Cardiovasc. Res. 55:369-374.

32. Aggoun, Y., et al. 2000. Mechanical properties of the common carotid artery in Williams syndrome. Heart. 84:290-293.

33. Berry, C.L., and Greenwald, S.E. 1976. Effects of hypertension on the static mechanical properties and chemical composition of the rat aorta. Cardiovasc. Res. 10:437-451.

34. Greenwald, S.E., and Barry, C.L. 1978. Static mechanical properties and chemical composition of the aorta of spontaneously hypertensive rats: a comparison with the effects of induced hypertension. Cardiovasc. Res. 12:364-372.

35. Brunner, H.R., Gavras, H., Laragh, J.H., and Keenan, R. 1973. Angiotensin-II blockade in man by $\mathrm{Sar}^{1}-\mathrm{Ala}^{8}$-angiotensin II for understanding and treatment of high blood-pressure. Lancet. 2:1045-1048.

36. Case, D.B., Wallace, J.M., Keim, H.J., Sealey, J.E., and Laragh, J.H. 1976. Usefulness and limitations of saralasin, a partial competitive agonist of angiotensin II, for evaluating the renin and sodium factors in hypertensive patients. Am. J. Med. 60:825-836.

37. Gavras, H., Gavras, I., Brunner, H.R., and Leiang, C.-S. 1979. Physio- logic studies with saralasin in animals. Kidney Int. 15(Suppl.):S20-S28. 38. Folkow, B. 1983. Structural autoregulation - the local adaptation of vascular beds to chronic changes in pressure. Ciba Found. Symp. 100:56-79.

39. Langille, B.L. 1996. Arterial remodeling: relation to hemodynamics. Can. J. Physiol. Pharmacol. 74:834-841.

40. Keeley, F.W., and Johnson, D.J. 1986. The effect of developing hypertension on the synthesis and accumulation of elastin in the aorta of the rat. Biochem. Cell Biol. 64:38-43.

41. Keeley, F.W., and Alatawi, A. 1991. Response of aortic elastin synthesis and accumulation to developing hypertension and the inhibitory effect of colchicine on this response. Lab. Invest. 64:499-507.

42. Bergwerff, M., DeRuiter, M.C., Poelmann, R.E., and Gittenberger-de Groot, A.C. 1996. Onset of elastogenesis and downregulation of smooth muscle actin as distinguishing phenomena in artery differentiation in the chick aorta. Anat. Embryol. (Berl.) 194:545-557.

43. Roach, M. 1983. The pattern of elastin in the aorta and large arteries of mammals. Ciba Found. Symp. 100:37-55.

44. Nakamura, H. 1988. Electron microscopic study of the prenatal development of the thoracic aorta in the rat. Am. J. Anat. 181:406-418.

45. Hungerford, J.E., and Little, C.D. 1998. Developmental biology of the vascular smooth muscle cell building a multilayered vessel wall. J. Vasc. Res. 36:2-27. 